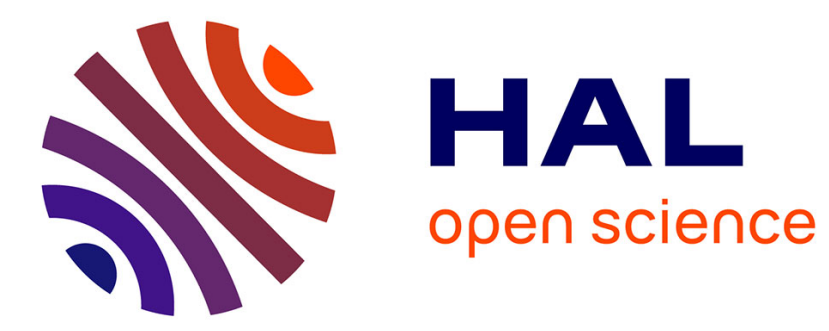

\title{
Cytokine-induced senescence for cancer surveillance
}

Thomas Wieder, Ellen Brenner, Heidi Braumüller, Oliver Bischof, Martin

Röcken

\section{To cite this version:}

Thomas Wieder, Ellen Brenner, Heidi Braumüller, Oliver Bischof, Martin Röcken. Cytokine-induced senescence for cancer surveillance. Cancer and Metastasis Reviews, 2017, 36 (2), pp.357-365. $10.1007 /$ s10555-017-9667-z . pasteur-03234890

\section{HAL Id: pasteur-03234890}

\section{https://hal-pasteur.archives-ouvertes.fr/pasteur-03234890}

Submitted on 25 May 2021

HAL is a multi-disciplinary open access archive for the deposit and dissemination of scientific research documents, whether they are published or not. The documents may come from teaching and research institutions in France or abroad, or from public or private research centers.
L'archive ouverte pluridisciplinaire HAL, est destinée au dépôt et à la diffusion de documents scientifiques de niveau recherche, publiés ou non, émanant des établissements d'enseignement et de recherche français ou étrangers, des laboratoires publics ou privés. 


\title{
Cytokine-induced senescence for cancer surveillance
}

\author{
Thomas Wieder $^{1} \cdot$ Ellen Brenner $^{1} \cdot$ Heidi Braumüller ${ }^{1}$ - Oliver Bischof ${ }^{2,3}$. \\ Martin Röcken ${ }^{1}$
}

Published online: 8 April 2017

(C) Springer Science+Business Media New York 2017

\begin{abstract}
The immune response is a first-line systemic defense to curb tumorigenesis and metastasis. Much effort has been invested to design antitumor interventions that would boost the immune system in its fight to defeat or contain cancerous growth. Tumor vaccination protocols, transfer of tumor-associatedantigen-specific $\mathrm{T}$ cells, $\mathrm{T}$ cell activity-regulating antibodies, and recombinant cytokines are counted among a toolbox filled with immunotherapeutic options. Although the mechanistic underpinnings of tumor immune control remain to be deciphered, these are studied with the goal of cancer cell destruction. In contrast, tumor dormancy is considered as a dangerous equilibrium between cell proliferation and cell death. There is, however, emerging evidence that tumor immune control can be achieved in the absence of overt cancer cell death. Here, we propose cytokine-induced senescence (CIS) by transfer of Thelper-1 cells $\left(T_{H} 1\right)$ or by recombinant cytokines as a novel therapeutic intervention for cancer treatment. Immunity-induced senescence triggers a stable cell cycle arrest of cancer cells. It engages the immune system to construct defensive, isolating barriers around tumors, and prevents tumor growth through the delivery or induction of $\mathrm{T}_{\mathrm{H}} 1$-cytokines in the tumor microenvironment. Keeping cancer cells in a non-proliferating state is a strategy, which directly copes with the lost homeostasis of aggressive tumors. As most studies
\end{abstract}

Thomas Wieder and Ellen Brenner contributed equally.

Thomas Wieder

thomas.wieder@med.uni-tuebingen.de

1 Department of Dermatology, Eberhard Karls University, Liebermeisterstr. 25, 72076 Tübingen, Germany

2 Nuclear Organization and Oncogenesis Unit, Department of Cell Biology and Infection, Institut Pasteur, 28, Rue du Dr. Roux, 75724 Paris, France

3 Inserm, U993, Paris, France show that even after efficient cancer therapies minimal residual disease persists, we suggest that therapies should include immune-mediated senescence for cancer surveillance. CIS has the goal to control the residual tumor and to transform a deadly disease into a state of silent tumor persistence.

Keywords Receptor-mediated growth arrest · Tumor dormancy $\cdot$ Inflammation $\cdot$ Cytokine-induced senescence

\section{Cellular senescence}

\subsection{The concept of cellular senescence}

Cellular senescence has been linked to a number of physiological and patho-physiological conditions such as aging, age-related diseases, tissue homeostasis, and embryogenesis (for review see [1]). In the context of aging of multicellular organisms, cellular senescence has been described as one of the nine hallmarks of aging. Besides, senescence is considered to be part of the compensatory or antagonistic damage responses [2]. Some senescence-associated biomarkers, foremost the cell cycle inhibitor cyclin-dependent kinase inhibitor $2 \mathrm{~A}\left(\mathrm{p} 16^{\mathrm{Ink} 4 \mathrm{a}}\right)$ and telomeredamage induced foci(TIFS), accumulate in cells of various tissues of aged individuals, indicating that senescence and aging are closely linked [3, 4]. Importantly, elimination of senescent cells from aged tissues improves overall tissue fitness [5], whereas the tissue-degenerative effects of senescence are likely to be transmitted by the senescence-associated secretory phenotype (SASP), at least in part [6] (Fig. 1a). Developmental senescence (Fig. 1b) is a physiologically programmed senescence pathway that has recently been described to actively contribute to embryonic patterning $[7,8]$. This process is also accompanied by a SASP that attracts macrophages which in turn seem to be necessary to remove senescent cells in a coordinate manner in order to foster the physical 
a)

$$
\begin{aligned}
& \text { Replicative } \\
& \text { senescence }
\end{aligned}
$$

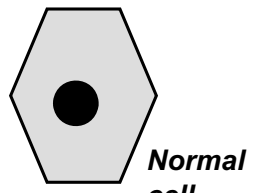

cell
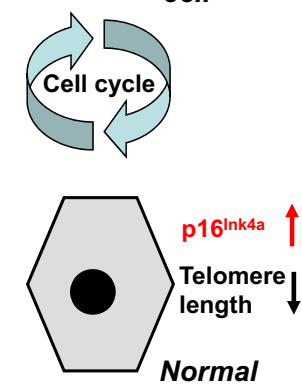

"old" cell

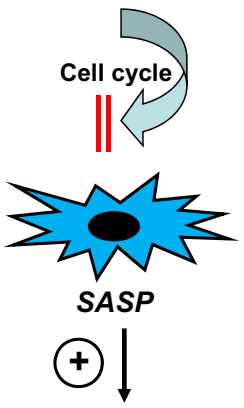

Tissue

degeneration b)

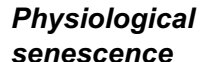

senescence

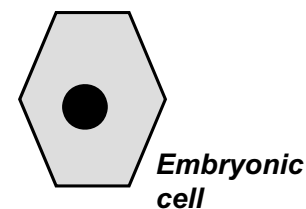

cell
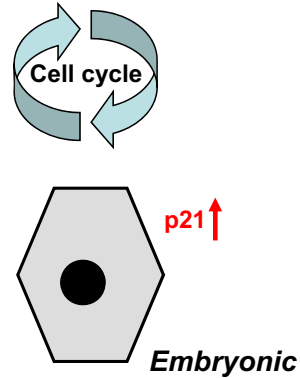

"old" cell

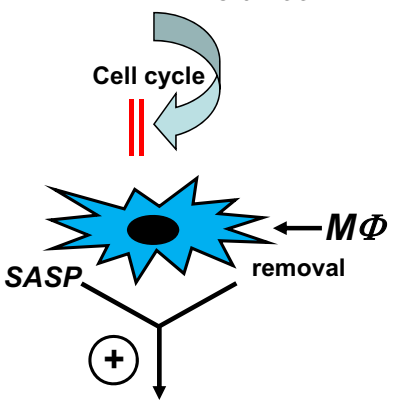

Tissue

shaping c) Oncogene- or therapy-induced senescence

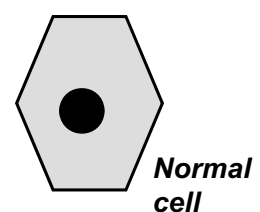

cell

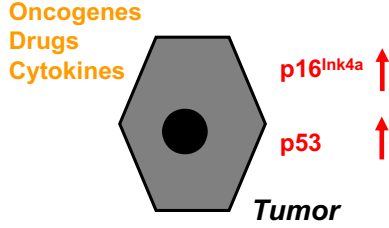

cell

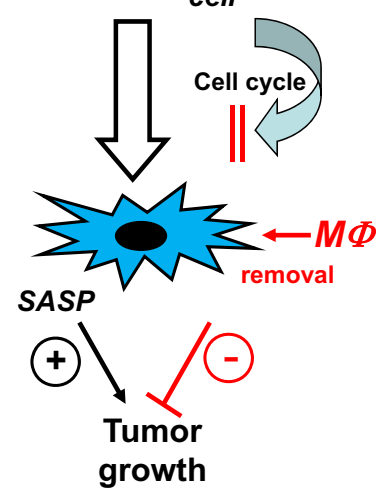

Fig. 1 Cellular senescence in aging, embryogenesis, and tumorgenesis. a During aging of the organism, normal cells may enter the cell cycle. After several cell divisions, the chromosomal telomere length decreases and the expression of the cell cycle inhibitor $\mathrm{p} 16^{\text {Ink4a }}$ increases. This leads to permanent arrest of the cell cycle and in the case of "old" cells to replicative senescence. Senescent cells produce secretory factors, and the SASP may contribute to enhanced tissue degeneration in older individuals. b During embryogenesis, some embryonic cells may run through the cell cycle leading to p53-independent p21 accumulation and permanent cell cycle arrest. On the one hand, these "old" embryonic cells produce secretory factors (SASP), and on the other hand, the senescent cells are cleared by macrophages. Both mechanisms then contribute to the tissue shaping during embryogenesis. c During

development of the embryo (Fig. 1b). In contrast, oncogene- or therapy-induced premature senescence is a mere stress response mechanism (Fig. 1c). It is a cell intrinsic anticancer mechanism that is triggered by various genetic or epigenetic perturbations including hyperactive oncogenes $[9,10]$, cytotoxic drugs $[11$, 12], or by cytokines [13-15] leading to an essentially irreversible cell cycle arrest. Oncogene-induced senescence is eventually accompanied by macrophage-mediated removal of the affected cancer cells, and this clearance mechanism of senescent cancers substantially improves the anti-cancer defense machinery of the immune system [16]. On the other hand, it is still unclear whether the tumorigenesis, normal cells may enter an accelerated cell cycle (for example by activation of oncogenes). These rapidly cycling tumor cells upregulate $\mathrm{p} 53$ and the cell cycle inhibitor $\mathrm{p} 16^{\text {Ink4a }}$ leading to permanent cell cycle arrest or oncogene-induced senescence. The tumor cells can also be driven into senescence by other cellular stressors, e.g., by drugs or cytokines. Interestingly, tumor cell senescence can both exert a pro- or antitumoral effect. Whereas the components of the SASP have been shown to enhance tumor growth, the macrophage-mediated clearance of senescent tumor cells inhibits tumor growth. $M \Phi$ macrophages, $p 16^{\text {Ink } 4 a}$ cyclin-dependent kinase inhibitor $2 \mathrm{~A}, p 21$ cyclin-dependent kinase inhibitor 1, p53 cellular tumor antigen p53, SASP senescence-associated secretory phenotype

SASP, which is an integral part of oncogene- as well as cytokineinduced senescence, and leads to the secretion of various chemokines and growth factors, may play a tumor-promoting role, and should therefore be considered as harmful [17]. Thus, it is currently believed that it is necessary to clear senescent cells from the organism.

\subsection{Cytokine-induced senescence}

Cytotoxic cancer therapy is currently the gold standard of clinical practice. A bevy of cytotoxic regimens has been 
developed over six decades to destroy or remove cancerous tissue. The complete surgical excision of cancer tissue including all adjacent or distant metastases is the most effective curative treatment option. It may be accompanied or followed by other mainly cytotoxic therapies, i.e., radiation therapy [18], chemotherapy [19], or cytotoxic immunotherapy [20, 21]. These therapies rely on (i) the induction of programmed cell death $[19,22]$; (ii) caspase-independent programmed necrotic cell death $[23,24]$ or necroptosis, that is dependent on the ripoptosome [25]; (iii) autophagic cell death [26]; (iv) target cell lysis [21]; and (v) respiratory burst mediated by neutrophils [27].

The common goal of all cytotoxic therapies is the ultimate destruction of the cancer cells [28]. In clear contrast, prosenescence therapy is not aimed at destroying cancer cells but to contain their expansion and thus can be considered as a non-destructive alternative tumor control mechanism [14, 15, 29-31]. In principle, cancer cell senescence can be triggered by intrinsic or extrinsic pathways (Fig. 2). The intrinsic pathways are triggered by reactivation/stabilization of the tumor suppressor protein p53 [32], by inactivation of the oncogene Myc [33], or by tumor suppressor phosphatase and tensin homolog deleted on chromosome 10 (Pten) inhibition by VO-OHpic [34]. Pten inhibition-induced senescence (PICS) in prostate cancer is especially intriguing, as loss of Pten is usually associated with oncogenesis, e.g., in aggressive breast cancer [35] or in follicular thyroid carcinomas [36]. Thus, the fate of a given precancerous cell after Pten loss may strongly depend on its ancestry and/or its molecular background. Nevertheless, the three intrinsic senescence pathways mentioned above lead to cell cycle arrest (Fig. 2a). The activation of these pathways results either in tumor growth inhibition or in tumor regression. Therapy-induced cancer cell senescence can be induced by genotoxic stress, i.e., by drugs targeting genomic DNA (Fig. 2b). Thus, doxorubicin [37] or cyclophosphamide treatment [12] induces a senescence-like phenotype in tumor cells. However, chemotherapeutics rather induce a mixed response including both apoptosis and senescence. In most cases, the senescent phenotype is only observed when the apoptosis machinery has been inhibited [12]. Thus, targeted therapies, like the B-Raf inhibitor vemurafenib, trigger senescence primarily in apoptosisresistant melanoma cells [38]. First hints that not only membrane-penetrating drugs with a low molecular weight can induce intrinsic senescence pathways came from the observation that cytokines, such as the T helper- $1\left(\mathrm{~T}_{\mathrm{H}} 1\right)$-cytokines interferon- $\gamma$ (IFN- $\gamma$ ) and tumor necrosis factor (TNF) [14] or transforming growth factor- $\beta$ (TGF- $\beta$ ) [13], can drive cancer cells into permanent growth arrest (Fig. 2c). This is astonishing as senescence was mainly considered to be an intrinsic antitumor mechanism. Cytokine-induced senescence (CIS) is the first example of an extrinsic senescence pathway leading to a permanent stop of the cell cycle. For the proinflammatory $T_{H} 1$ cytokines, the senescence signaling pathways have been partially deciphered: permanent growth arrest needs the simultaneous activation of TNF receptor 1 , IFN- $\gamma$-signaling, and downstream stabilization of the prosenescent $\mathrm{p} 16^{\text {Ink4a }} / \mathrm{Rb}$ pathway $[14,15]$. CIS also occurs in vivo after adoptive transfer of tumor-associated antigen (TAA)-specific $\mathrm{T}_{\mathrm{H}} 1$ cells in transgenic rat-insulin promoter $\mathrm{T}$ antigen (RIP-Tag) mice (Fig. 2d) [14], or after vaccination of sarcoma-bearing mice with an IL-12 transcribing gene construct that induces IFN- $\gamma$ - and TNF-mediated immune responses [15]. This demonstrates for the first time that (i) exogenous signals can override endogenous proliferative signals in cancer cells and (ii) that the immune system is able to restrict cancer growth by senescence induction without eradication of the cancer cells.

\section{The immune system strikes back}

\subsection{Immune destruction and immune surveillance of cancer}

Apart from the destruction of tumor cells by chemotherapy, radiation therapy or cytotoxic immune therapy, novel treatment options appear that control cancers without complete eradication. Some of these treatment options take advantage of the immune system: (i) adoptive transfer of tumor-specific, non-cytotoxic $\mathrm{T}$ helper cells may lead to durable clinical remission in melanoma patients [39] or to tumor dormancy in TAA-driven islet-cell cancer [40] and (ii) enhancement of T cell-mediated antitumor immune response in patients with stage IV melanoma or non-small-cell lung cancer. Here, blocking antibodies directed against immune checkpoints, e.g., primary monoclonal antibodies (mAbs) against the programmed death 1 (PD-1) receptor or its ligand PD-L1. The therapeutic efficiency may be enhanced by combining these $\mathrm{mAbs}$ with a mAb against cytotoxic T-lymphocyte-associated antigen 4 (CTLA-4) [41-44]. The mechanisms underlying the observed immunotherapeutic effects are still to be defined in detail. These antibodies can destroy cancers at least in part [45]. However, under most conditions, tumors of patients are not completely eradicated and the responding patients continue to live with stable disease. Thus, at the beginning of immune checkpoint inhibitor therapies, the tumor load tends to decline, most probably due to infiltration of cytotoxic immune cells [42, 43, 46-49]. After this first cytotoxic phase, the remaining tumor or metastases tend to stay at a constant level but will not disappear [50, 51]. This indicates that immunotherapy may follow the defensive wall concept, which relies on non-toxic control of the tumor burden [52-54] and which is based on the induction of tumor dormancy. Tumor dormancy is considered as an equilibrium between cancer cell proliferation and killing of cancer cells $[55,56]$ with apoptosis or 
Intrinsic pathways

a)

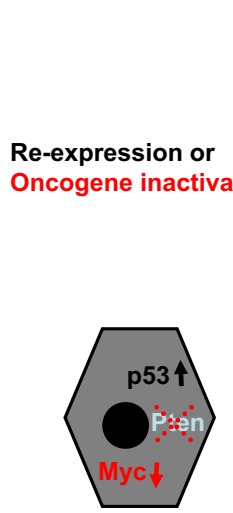

Tumor cell

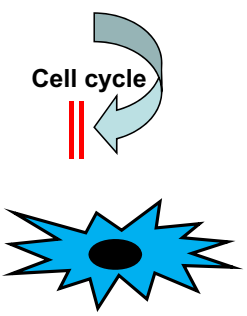

b)

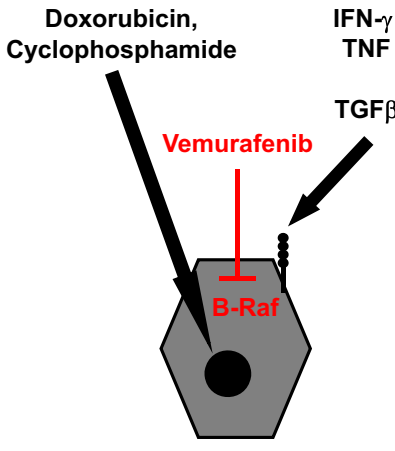

Tumor cell

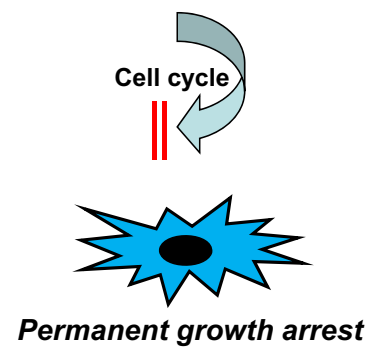

Extrinsic pathways

d)

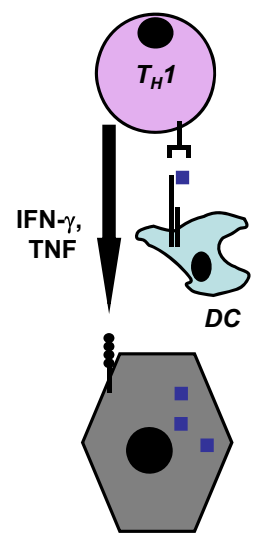

Tumor cell

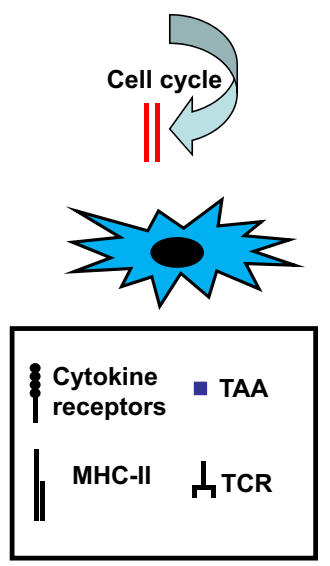

Fig. 2 Pathways of therapy-induced tumor cell senescence. Tumor cell senescence during therapy is induced either by intrinsic $(\mathbf{a}, \mathbf{b})$ or extrinsic pathways (c, d). a Molecular induction of cellular senescence can be realized by reexpression of pro-senescence factors (e.g., p53), complete loss of Pten, or oncogene inactivation (e.g., Myc). These molecular manipulations eventually lead to permanent growth arrest of tumor cells. b Different drugs, such as doxorubicin or cyclophosphamide, target the DNA of the cycling tumor cells leading to DNA stress which in turn induces a permanent cell cycle arrest. More specific drugs, e.g., the B-Raf kinase inhibitor vemurafenib, target intracellular signaling pathways and also lead to permanent cell cycle arrest. c Different cytokines, such as IFN- $\gamma$, TNF or TGF- $\beta$, bind to their specific receptors on the surface of the tumor cells. Activation of the cytokine

immune cell-mediated lysis of cancer cells being the main killing mechanisms. This interpretation of the state of silent tumors has now been complemented by four non-toxic mechanisms, namely (i) active cell cycle control through regulation of cyclin-dependent kinases [57]; (ii) induction of cellular senescence [9, 14, 15, 58]; (iii) control of differentiation by regulating inhibitor of DNA binding (ID) proteins [59]; and (iv) inhibition of angiogenesis [60].

Evasion from immune-mediated control of tumors has been added to the six original hallmarks of cancer [61]. As shown in Fig. 3, control of tumors by the immune system can receptors then triggers intracellular signaling pathways leading to permanent cell cycle arrest. d Immune cells are also able to induce extrinsic senescence in tumor cells. Here, tumor-specific $\mathrm{T}_{\mathrm{H}} 1$ cells are activated by MHC-II-positive DCs. After activation, the $\mathrm{T}_{\mathrm{H}} 1$ cells secrete the soluble factors IFN- $\gamma$ and TNF in the vicinity of the tumors. The secreted cytokines then bind to their specific receptors on the surface of the tumor cells thereby activating intracellular senescence pathways. $B R A F$ proto-oncogene B-Raf or v-Raf murine sarcoma viral oncogene homolog B1, DC dendritic cells, IFN- $\gamma$ interferon- $\gamma, M H C-I I$ major histocompatibility complex class II, p53 cellular tumor antigen p53, Pten phosphatase and tensin homolog deleted on chromosome 10, TAA tumor-associated antigen, $T C R \mathrm{~T}$ cell receptor, $T G F-\beta$ transforming growth factor- $\beta, T_{H} l$ T helper-1 cells, TNF tumor necrosis factor

be divided into a cytotoxic branch leading to tumor eradication and a non-cytotoxic branch leading either to stable disease or tumor regression. Immune destruction of tumors relies on cellular immunity: (i) cytotoxic T cells (CTLs) (Fig. 3a) or natural killer cells (NK) (Fig. 3b) specifically attack tumors by releasing pore-forming perforin together with proteases such as granzyme B or soluble toxic factors such as TNF [55, 56, 62-64]; (ii) specific CTLs may directly target the cancer cells by inducing death receptor-dependent apoptosis via the cluster of differentiation 95 ligand/cluster of differentiation 95 (CD95L/CD95) death-inducing signaling complex (for 
Immune destruction

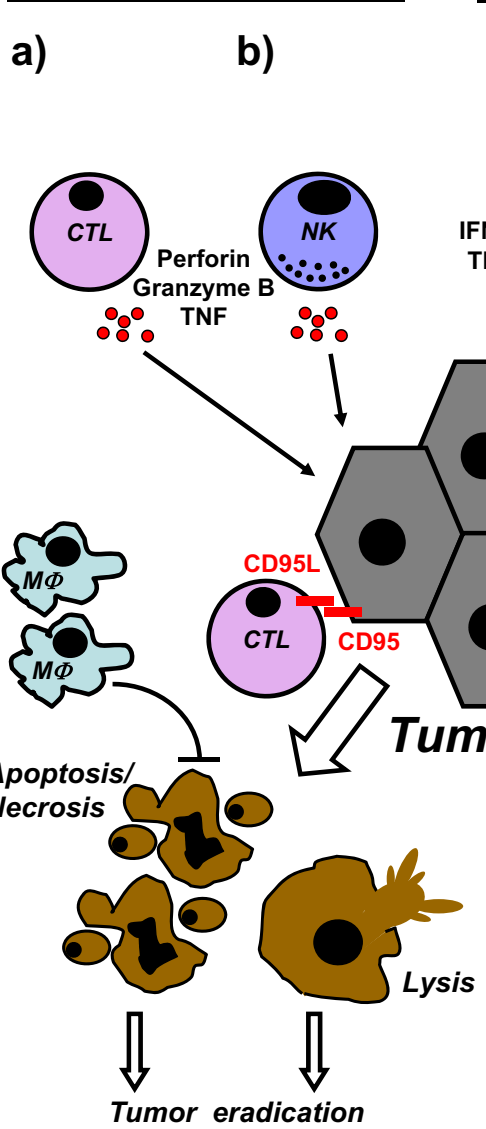

Fig. 3 Toxic and non-toxic pathways of immune system-mediated tumor suppression. The control of tumors by the immune system is achieved by immune destruction $(\mathbf{a}, \mathbf{b})$ or immune surveillance $(\mathbf{c}, \mathbf{d})$. a CTL either indirectly or directly attack tumor cells by secretion of toxic factors, such as perforin, granzyme $\mathrm{B}$, or TNF, or by planting a kiss of death via CD95L-CD95 interaction and induction of the apoptosis cascade. This leads to tumor cell death by apoptosis, clearance of apoptotic bodies by macrophages, necrosis, or to tumor cell lysis. Finally, the immune system completely eradicates the tumor. b NK cells, like CTL, indirectly attack tumor cells by secretion of toxic substances, such as perforin, granzyme $\mathrm{B}$, or TNF. This leads to tumor cell death and complete eradication of the tumor. $\mathbf{c} \mathrm{T}_{\mathrm{H}} 1$ cells or macrophages silence tumor cells by secretion of IFN- $\gamma$ and TNF or TGF- $\beta$, respectively. After binding to their specific

review see [62]). If tumor immune destruction is successful, the apoptotic cells will be cleared by macrophages and the tumors will be eradicated. In addition, it has been shown that the immune system can also control tumors by senescence surveillance, a mechanism mainly based on cytokineinduced cellular senescence (Fig. 3c) and an immune-cellmediated clearance pathway (Fig. 3d). Senescence has been shown to be induced in vivo in murine islet cell tumors by a combination of IFN- $\gamma$ and TNF released from tumor-specific $\mathrm{T}_{\mathrm{H}} 1$ cells in the vicinity of the tumors [14]. Similarly, human sarcoma cell lines can be driven into senescence by IL-12mediated induction of a $\mathrm{T}_{\mathrm{H}} 1$-phenotype in human $\mathrm{T}$ cells [15]. In this line, it has been demonstrated that the loss of
Immune surveillance

c)

d)

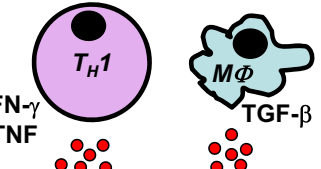

$\because$
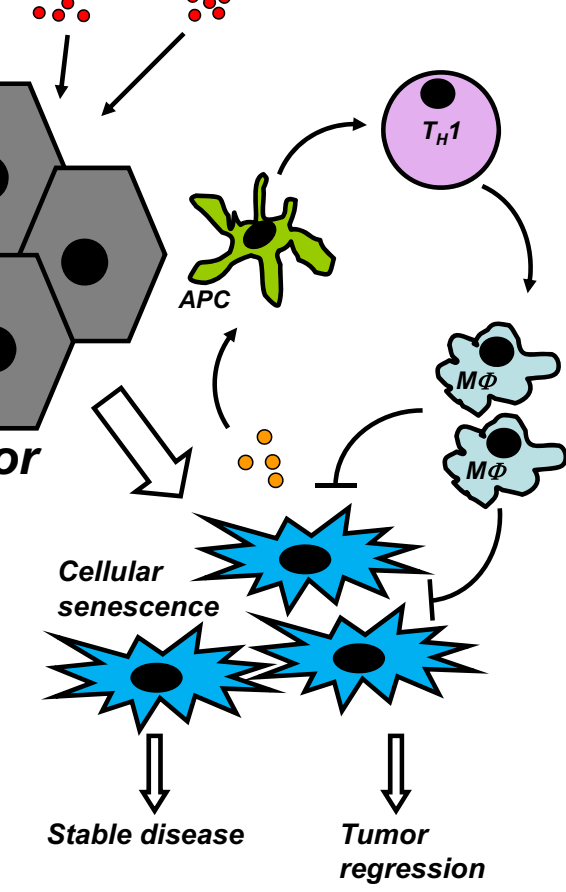

receptors on the surface of the tumor cells, the cytokines activate intracellular senescence pathways leading to permanent cell cycle arrest and stable disease. d Senescent tumor cells may also be cleared. Molecular factors released by senescent tumor cells lead to activation of APC. The APCs then stimulate a $\mathrm{T}_{\mathrm{H}} 1$ cell response followed by activation of macrophages which in turn mediate the clearance of senescent cancer cells. If senescence induction and subsequent clearance of senescent tumor cells is effective, immune surveillance may also induce tumor regression. APC antigen-presenting cells, CD95 cluster of differentiation $95, C D 95 \mathrm{~L}$ cluster of differentiation 95 ligand, $C T L$ cytotoxic T cells, $I F N-\gamma$ interferon- $\gamma, M \Phi$ macrophages cells, $N K$ natural killer cells, $T G F-\beta$ transforming growth factor- $\beta, T_{H} 1$ T helper-1, $T N F$ tumor necrosis factor

IFN- $\gamma$ pathway genes in cancer cells serves as a mechanism of resistance during immune checkpoint inhibitor therapies [65] and that the disruption of cyclin-dependent kinase 5 (Cdk5) strengthens antitumor immunity [66]. Likewise, TGF- $\beta$ originating from macrophages was shown to induce cellular senescence in lymphoma cells [13]. Thus, senescence induction alone leads to permanent growth arrest and stable disease with a remarkable prolongation of the survival of death-prone RIP-Tag mice [40]. In the long run, however, it may be necessary that senescent cancer cells become cleared: the SASP of N-ras-expressing senescent hepatocytes leads to activation of professional antigen-presenting cells (APCs) which in turn drive a $T_{H} 1$ cell response followed by activation 
of macrophages. One concept then suggests the subsequent clearance of senescent cancer cells by activated macrophages [16]. Yet, it remains unclear whether elimination of senescent cells always supports cancer cure or whether it may on the contrary promote cancer progression [67]. Senescenceinducing treatment of cancer patients is apparently based on re-enhancement or restoration of dormant intrinsic pathways. As survival with silenced tumors or with disseminated, silenced tumor cells is possible [41, 52], cancer patients will benefit from successful restoration of intrinsic senescence surveillance. In addition, it is likely that the resulting side effects of non-cytotoxic, pro-senescence therapies should be less severe as compared with cytotoxic regimens [68]. However, similar to cytotoxic tumor treatment, the benefits of prosenescence therapy described above are only effective if the vast majority of the tumor cells is driven into senescence. Furthermore, the resting state of the silenced cancer cells has to be maintained, either by a permanent growth arrest or by exogenous (immune)-signals that keep the cancer cells silent. The main problems of senescence surveillance of tumors which have to be solved in the near future are therefore: (i) fast growing tumor cells, e.g., acute leukemias, may escape senescence surveillance $[14,15]$; (ii) resting tumor cells may eventually awake and start regrowing if CIS turns out to be reversible, at least in some very aggressive cancers; (iii) the fate of non-proliferating tumor stem cells is unclear; (iv) the regeneration of normal tissues may be impaired; and (v) chronic inflammation [61] and some molecular components of the SASP [1, 17, 69] may even promote tumorigenesis in neighboring premalignant cells.

\subsection{Evolutionary aspects of immune destruction and immune surveillance of cancer}

Eradication of tumors is mainly based on cytotoxic principles, and the biological targets of different chemotherapeutics are genomic DNA (genetic code) as in the case of epirubicin [22], the plasma membrane (outward demarcation of the cell) as in the case of miltefosin [70], or the cytoskeleton as in the case of taxol [22]. This holds also true for the destruction of tumors by the immune system. It is generally accepted that apoptosis induction by death receptors (e. g., CD95/CD95L, TNF/ TNFR1, etc.) finally leads to caspase-dependent DNA fragmentation $[19,22,62]$ whereas the perforin/granzyme B system leads to target cell lysis, cell membrane rupture, and activation of specialized serine proteases [63, 64]. However, if DNA fragmentation is incomplete, mutated tumor cell clones might emerge and a Darwinian selection process is triggered [71]. This is to say that the vast majority of mutated tumor cells carrying large genomic aberrations (such as loss or gain of whole chromosome arms) will die, but those mutated cells that survive will restart proliferation and lose important endogenous or exogenous control mechanisms. Uncontrolled proliferation then leads to accumulation of additional DNA damage and chromosomal chaos. Together, the genetic instability of cancers and the highly selective local microenvironmental forces, e.g., hypoxia, acidosis, and reactive oxygen species, are able to further promote somatic evolution. In addition, cytotoxic regimens impose strong selection pressures on the surviving cancer cells; the treatment should therefore rather enhance the evolutionary rate and promote selection of mutated cancer clones [71].

In clear contrast to conventional chemotherapy, immune surveillance of tumors is not exclusively dependent on tumor cell destruction, and the biological target structures are mainly signal transduction pathways and the respective signaling molecules, e.g., receptors, adaptor proteins, kinases, or kinase inhibitors. For example, CIS by $\mathrm{T}_{\mathrm{H}} 1$ cell cytokines (IFN- $\gamma$, TNF etc.) leads to stabilization of the $\mathrm{p} 16^{\text {Ink } 4 \mathrm{a}} / \mathrm{Rb}$ pathway thereby permanently arresting the tumor cells in the G0/G1 phase of the cell cycle [14]. Furthermore, tumor-specific $T_{H} 1$ cells that can now be generated for the use in humans [72] induce the production of antiangiogenic chemokines, e.g., chemokine (C-X-C motif) ligand 9 (CXCL9) and chemokine (C-X-C motif) ligand 10 (CXCL10) [14, 40] thereby leading to isolation of the tumor cells $[40,54]$. Inhibitory antibodies, on the other hand, target cellular exhaustion pathways by interfering with ligand-receptor interactions thereby maintaining the antitumoral activity of specific immune cells [41]. Last but not least, small molecules targeting signal transduction pathways, such as proto-oncogene B-Raf (BRAF) inhibitors or oncogenic BCR-ABL gene fusion product (BCR-ABL) inhibitors, specifically inhibit kinases thereby driving the cancer cells into cell cycle arrest [38]. The common feature of those strategies is that they directly or indirectly impair cancer cell proliferation. The selection pressure on the arrested cancer cells is therefore strongly reduced and the treatment should not promote somatic evolution.

\subsection{Metabolic aspects of immune destruction and immune surveillance of cancer cells}

Cancer cells are distinct from normal cells as they switch from aerobic to anaerobic metabolism, even in the presence of sufficient oxygen support. Thus, they use anaerobic glycolysis for adenosin triphosphate (ATP) production rather than oxidative phosphorylation, the so called Warburg effect $[1,61]$. As a result, the oxygen consumption by the mitochondria is reduced. The cells produce lactic acid which is released into the blood and transported to the liver where it is used for gluconeogenesis.

Chemotherapy- or radiation therapy-induced apoptosis should enhance the switch of tumors towards anaerobic metabolism. In this line, it has been shown that drug-induced apoptosis signaling leads to dissipation of the mitochondrial membrane potential, release of cytochrome c, and 
downstream activation of caspase-3 [22, 73]. Thus, oxidative phosphorylation via the mitochondrial respiratory chain is further inhibited during drug-induced apoptosis.

On the other hand, cancer cells undergoing oncogeneinduced senescence (OIS) switch back to mitochondrial oxidative phosphorylation. By regulating the mitochondrial gate keeper pyruvate dehydrogenase, senescent cells make enhanced use of pyruvate in the tricarboxylic acid cycle [74]. This causes increased respiration and oxidative stress thereby counteracting metabolic reprogramming in the cancer cells. Interestingly, premature senescence is often accompanied by activation of the target of rapamycin (TOR) pathway which is considered to be a central regulator of mammalian metabolism and physiology. Activation of TOR in the context of cell cycle arrest then leads to real senescence with irreversible loss of the regenerative potential [75]. Metabolic reprogramming as seen by the Warburg effect provides tumor cells with ATP and with the substrates required for biomass generation. Recently, it was demonstrated that the mitochondrial nicotinamide adenine dinucleotide (NAD)-dependent deacetylase SIRT3 is a crucial regulator of the Warburg effect by destabilizing hypoxia-inducible factor- $1 \alpha$ (HIF- $1 \alpha)$. HIF- $1 \alpha$ downregulation then leads to repression of glycolysis and inhibition of proliferation of breast cancer cells thereby pointing to a new tumor suppressor mechanism [76]. Activation of the immune system is also connected with cellular metabolism. It has been shown that succinate, an important metabolite of the tricarboxylic acid cycle, serves as an inflammatory signal that induces interleukin-1 $\beta$ (IL-1 $\beta$ ) through HIF-1 $\alpha$ [77]. Thus, there are several experimental hints that tight connections between the regulation pathways of the cell cycle and the main metabolic pathways of eukaryotic cells, i.e., glycolysis, tricarboxylic acid cycle, and oxidative phosphorylation, really exist. Future work will decipher the signaling networks underlying inflammation, oncogenesis, cancer cell senescence, and metabolic reprogramming.

\section{Outlook: combining cytotoxic and pro-senescence therapy}

Due to the still unsatisfactory clinical success of cancer treatments, additional efforts including new concepts are urgently needed. As therapy resistance is the most important drawback of the main cytotoxic cancer regimens, it is reasonable to target different cellular structures or hallmarks of cancer. Nevertheless, a combination approach may even be successful if similar cellular signaling pathways are inhibited or induced at the same time. For example, the combination of $\mathrm{T}$ cellactivating anti-PD- 1 and anti-CTLA-4 antibodies showed improved clinical activity that clearly exceeded monotherapy [41]. The finding that it is possible to induce extrinsic premature senescence by treatment of cancer cells with a cytokine combination of IFN- $\gamma$ and TNF [14] opens the way to nontoxic treatment options. Both cytokines are endogenous signaling molecules which are already available as drugs. Their toxicity profiles are known and less toxic alternatives, such as IFN- $\alpha$, are at hand. More importantly, stopping the fulminant growth of malignant cancers by CIS will thus perfectly complement the cytotoxic effect of most anti-cancer drugs. The combination of cytotoxic drugs in the acute phase of the disease with CIS as therapy during the consolidation phase is one of the most promising approaches which may be introduced into clinical practice in the near future. In conclusion, besides the development and introduction of new drugs for cancer cell destruction or senescence induction, clinical research should also focus on optimized strategies that combine already approved medication with CIS.

Acknowledgments The work of the authors is supported by the Sander Stiftung (2012.056.1, 2012.056.2 and 2012.056.3), the Deutsche Krebshilfe (No. 109037 and 110664), the Deutsche Forschungsgemeinschaft (DFG WI 1279/4-1 and Sonderforschungsbereich SFB 685) and Fondation ARC pour la recherche sur le Cancer, Agence Nationale Recherche ANR, Fondation Pasteur-Weizmann, and Association LNCC La Ligue National Contre le Cancer. O. Bischof is CNRS-DR2.

\section{Compliance with ethical standards}

Conflict of interest The authors declare that they have no conflict of interest.

\section{References}

1. Perez-Mancera, P. A., Young, A. R., \& Narita, M. (2014). Inside and out: the activities of senescence in cancer. Nature Reviews: Cancer, 14(8), 547-558.

2. Lopez-Otin, C., Blasco, M. A., Partridge, L., Serrano, M., \& Kroemer, G. (2013). The hallmarks of aging. Cell, 153(6), 1194 1217.

3. Fumagalli, M., Rossiello, F., Clerici, M., Barozzi, S., Cittaro, D., Kaplunov, J. M., et al. (2012). Telomeric DNA damage is irreparable and causes persistent DNA-damage-response activation. Nature Cell Biology, 14(4), 355-365.

4. Burd, C. E., Sorrentino, J. A., Clark, K. S., Darr, D. B., Krishnamurthy, J., Deal, A. M., et al. (2013). Monitoring tumorigenesis and senescence in vivo with a p16(INK4a)-luciferase model. Cell, 152(1-2), 340-351.

5. Baker, D. J., Wijshake, T., Tchkonia, T., LeBrasseur, N. K., Childs, B. G., van de Sluis, B., et al. (2011). Clearance of p16Ink4a-positive senescent cells delays ageing-associated disorders. Nature, 479(7372), 232-236.

6. Campisi, J., Andersen, J. K., Kapahi, P., \& Melov, S. (2011). Cellular senescence: a link between cancer and age-related degenerative disease? Seminars in Cancer Biology, 21(6), 354-359.

7. Munoz-Espin, D., Canamero, M., Maraver, A., Gomez-Lopez, G., Contreras, J., Murillo-Cuesta, S., et al. (2013). Programmed cell senescence during mammalian embryonic development. Cell, 155(5), 1104-1118.

8. Storer, M., Mas, A., Robert-Moreno, A., Pecoraro, M., Ortells, M. C., Di Giacomo, V., et al. (2013). Senescence is a developmental 
mechanism that contributes to embryonic growth and patterning. Cell, 155(5), 1119-1130.

9. Michaloglou, C., Vredeveld, L. C., Soengas, M. S., Denoyelle, C., Kuilman, T., van der Horst, C. M., et al. (2005). BRAFE600associated senescence-like cell cycle arrest of human naevi. Nature, 436(7051), 720-724.

10. Lee, S., Schmitt, C. A., \& Reimann, M. (2011). The Myc/ macrophage tango: oncogene-induced senescence, Myc style. Seminars in Cancer Biology, 21(6), 377-384.

11. Chang, B. D., Broude, E. V., Dokmanovic, M., Zhu, H., Ruth, A., Xuan, Y., et al. (1999). A senescence-like phenotype distinguishes tumor cells that undergo terminal proliferation arrest after exposure to anticancer agents. Cancer Research, 59(15), 3761-3767.

12. Schmitt, C. A., Fridman, J. S., Yang, M., Lee, S., Baranov, E., Hoffman, R. M., et al. (2002). A senescence program controlled by $\mathrm{p} 53$ and $\mathrm{p} 16 \mathrm{INK} 4 \mathrm{a}$ contributes to the outcome of cancer therapy. Cell, 109(3), 335-346.

13. Reimann, M., Lee, S., Loddenkemper, C., Dorr, J. R., Tabor, V., Aichele, P., et al. (2010). Tumor stroma-derived TGF-beta limits myc-driven lymphomagenesis via Suv39h1-dependent senescence. Cancer Cell, 17(3), 262-272.

14. Braumüller, H., Wieder, T., Brenner, E., Assmann, S., Hahn, M., Alkhaled, M., et al. (2013). T-helper-1-cell cytokines drive cancer into senescence. Nature, 494(7437), 361-365.

15. Schilbach, K., Alkhaled, M., Welker, C., Eckert, F., Blank, G., Ziegler, H., et al. (2015). Cancer-targeted IL-12 controls human rhabdomyosarcoma by senescence induction and myogenic differentiation. OncoImmunology, 4(7), e1014760.

16. Kang, T.-W., Yevsa, T., Woller, N., Hoenicke, L., Wuestefeld, T., Dauch, D., et al. (2011). Senescence surveillance of pre-malignant hepatocytes limits liver cancer development. Nature, 479(7374), 547-551. doi:10.1038/nature10599.

17. Campisi, J. (2013). Aging, cellular senescence, and cancer. Annual Review of Physiology, 75, 685-705.

18. Durante, M., \& Loeffler, J. S. (2010). Charged particles in radiation oncology. Nature Reviews: Clinical Oncology, 7(1), 37-43.

19. Friesen, C., Herr, I., Krammer, P. H., \& Debatin, K. M. (1996). Involvement of the CD95 (APO-1/FAS) receptor/ligand system in drug-induced apoptosis in leukemia cells. Nature Medicine, 2(5), 574-577.

20. Mocikat, R., Braumüller, H., Gumy, A., Egeter, O., Ziegler, H., Reusch, U., et al. (2003). Natural killer cells activated by MHC class I (low) targets prime dendritic cells to induce protective CD8 T cell responses. Immunity, 19(4), 561-569.

21. Baum, V., Buhler, P., Gierschner, D., Herchenbach, D., Fiala, G. J., Schamel, W. W., et al. (2013). Antitumor activities of PSMAxCD3 diabodies by redirected T-cell lysis of prostate cancer cells. Immunotherapy, 5(1), 27-38.

22. Wieder, T., Essmann, F., Prokop, A., Schmelz, K., Schulze-Osthoff, K., Beyaert, R., et al. (2001). Activation of caspase-8 in druginduced apoptosis of B-lymphoid cells is independent of CD95/Fas receptor-ligand interaction and occurs downstream of caspase-3. Blood, 97(5), 1378-1387.

23. Scholz, C., Wieder, T., Starck, L., Essmann, F., Schulze-Osthoff, K., Dörken, B., et al. (2005). Arsenic trioxide triggers a regulated form of caspase-independent necrotic cell death via the mitochondrial death pathway. Oncogene, 24(11), 1904-1913.

24. Boujrad, H., Gubkina, O., Robert, N., Krantic, S., \& Susin, S. A. (2007). AIF-mediated programmed necrosis: a highly regulated way to die. Cell Cycle, 6(21), 2612-2619.

25. Feoktistova, M., Geserick, P., Panayotova-Dimitrova, D., \& Leverkus, M. (2012). Pick your poison: the Ripoptosome, a cell death platform regulating apoptosis and necroptosis. Cell Cycle, 11(3), 460-467.

26. Wang, Y., Zhan, Y., Xu, R., Shao, R., Jiang, J., \& Wang, Z. (2015). Src mediates extracellular signal-regulated kinase $1 / 2$ activation and autophagic cell death induced by cardiac glycosides in human nonsmall cell lung cancer cell lines. Molecular Carcinogenesis, 54(Suppl 1), E26-E34.

27. van Spriel, A. B., Leusen, J. H., van Egmond, M., Dijkman, H. B., Assmann, K. J., Mayadas, T. N., et al. (2001). Mac-1 (CD11b/ $\mathrm{CD} 18$ ) is essential for Fc receptor-mediated neutrophil cytotoxicity and immunologic synapse formation. Blood, 97(8), 2478-2486.

28. Sporn, M. B. (1996). The war on cancer. Lancet, 347(9012), 1377 1381.

29. Ewald, J. A., Desotelle, J. A., Wilding, G., \& Jarrard, D. F. (2010). Therapy-induced senescence in cancer. Journal of the National Cancer Institute, 102(20), 1536-1546.

30. Nardella, C., Clohessy, J. G., Alimonti, A., \& Pandolfi, P. P. (2011). Pro-senescence therapy for cancer treatment. Nature Reviews: Cancer, 11(7), 503-511.

31. Acosta, J. C., \& Gil, J. (2012). Senescence: a new weapon for cancer therapy. Trends in Cell Biology, 22(4), 211-219.

32. Xue, W., Zender, L., Miething, C., Dickins, R. A., Hernando, E., Krizhanovsky, V., et al. (2007). Senescence and tumour clearance is triggered by p53 restoration in murine liver carcinomas. Nature, 445(7128), 656-660. doi:10.1038/nature05529.

33. Rakhra, K., Bachireddy, P., Zabuawala, T., Zeiser, R., Xu, L., Kopelman, A., et al. (2010). CD4(+) T cells contribute to the remodeling of the microenvironment required for sustained tumor regression upon oncogene inactivation. Cancer Cell, 18(5), 485498.

34. Alimonti, A., Nardella, C., Chen, Z., Clohessy, J. G., Carracedo, A., Trotman, L. C., et al. (2010). A novel type of cellular senescence that can be enhanced in mouse models and human tumor xenografts to suppress prostate tumorigenesis. Journal of Clinical Investigation, 120(3), 681-693.

35. Boelens, M. C., Nethe, M., Klarenbeek, S., de Ruiter, J. R., Schut, E., Bonzanni, N., et al. (2016). PTEN loss in E-cadherin-deficient mouse mammary epithelial cells rescues apoptosis and results in development of classical invasive lobular carcinoma. Cell Reports, 16(8), 2087-2101

36. Jolly, L. A., Massoll, N., \& Franco, A. T. (2016). Immune suppression mediated by myeloid and lymphoid derived immune cells in the tumor microenvironment facilitates progression of thyroid cancers driven by HrasG12V and Pten loss. Journal of Clinical \& Cellular Immunology, 7(5), 451.

37. Benhamed, M., Herbig, U., Ye, T., Dejean, A., \& Bischof, O. (2012). Senescence is an endogenous trigger for microRNAdirected transcriptional gene silencing in human cells. Nature Cell Biology, 14(3), 266-275.

38. Haferkamp, S., Borst, A., Adam, C., Becker, T. M., Motschenbacher, S., Windhovel, S., et al. (2013). Vemurafenib induces senescence features in melanoma cells. Journal of Investigative Dermatology, 133(6), 1601-1609.

39. Hunder, N. N., Wallen, H., Cao, J., Hendricks, D. W., Reilly, J. Z., Rodmyre, R., et al. (2008). Treatment of metastatic melanoma with autologous CD4+ T cells against NY-ESO-1. New England Journal of Medicine, 358(25), 2698-2703.

40. Müller-Hermelink, N., Braumüller, H., Pichler, B., Wieder, T., Mailhammer, R., Schaak, K., et al. (2008). TNFR1 signaling and IFN-gamma signaling determine whether T cells induce tumor dormancy or promote multistage carcinogenesis. Cancer Cell, 13(6), 507-518.

41. Wolchok, J. D., Kluger, H., Callahan, M. K., Postow, M. A., Rizvi, N. A., Lesokhin, A. M., et al. (2013). Nivolumab plus ipilimumab in advanced melanoma. New England Journal of Medicine, 369(2), 122-133.

42. Robert, C., Long, G. V., Brady, B., Dutriaux, C., Maio, M., Mortier, L., et al. (2015). Nivolumab in previously untreated melanoma without BRAF mutation. New England Journal of Medicine, 372(4), 320-330. 
43. Borghaei, H., Paz-Ares, L., Horn, L., Spigel, D. R., Steins, M., Ready, N. E., et al. (2015). Nivolumab versus docetaxel in advanced nonsquamous non-small-cell lung cancer. New England Journal of Medicine, 373(17), 1627-1639.

44. Herbst, R. S., Soria, J. C., Kowanetz, M., Fine, G. D., Hamid, O., Gordon, M. S., et al. (2014). Predictive correlates of response to the anti-PD-L1 antibody MPDL3280A in cancer patients. Nature, 515(7528), 563-567.

45. Tumeh, P. C., Harview, C. L., Yearley, J. H., Shintaku, I. P., Taylor, E. J., Robert, L., et al. (2014). PD-1 blockade induces responses by inhibiting adaptive immune resistance. Nature, 515(7528), 568571.

46. Larkin, J., Chiarion-Sileni, V., Gonzalez, R., Grob, J. J., Cowey, C. L., \& Lao, C. D., et al. (2015). Combined nivolumab and ipilimumab or monotherapy in untreated melanoma. New England Journal of Medicine.

47. Le, D. T., Uram, J. N., Wang, H., Bartlett, B. R., Kemberling, H., Eyring, A. D., et al. (2015). PD-1 blockade in tumors with mismatch-repair deficiency. New England Journal of Medicine, 372(26), 2509-2520.

48. Rosenberg, J. E., Hoffman-Censits, J., Powles, T., van der Heijden, M. S., Balar, A. V., Necchi, A., et al. (2016). Atezolizumab in patients with locally advanced and metastatic urothelial carcinoma who have progressed following treatment with platinum-based chemotherapy: a single-arm, multicentre, phase 2 trial. Lancet, 387(10031), 1909-1920.

49. Mlecnik, B., Bindea, G., Angell, H. K., Maby, P., Angelova, M., Tougeron, D., et al. (2016). Integrative analyses of colorectal cancer show immunoscore is a stronger predictor of patient survival than microsatellite instability. Immunity, 44(3), 698-711.

50. Topalian, S. L., Hodi, F. S., Brahmer, J. R., Gettinger, S. N., Smith, D. C., McDermott, D. F., et al. (2012). Safety, activity, and immune correlates of anti-PD-1 antibody in cancer. New England Journal of Medicine, 366(26), 2443-2454.

51. Brahmer, J. R., Tykodi, S. S., Chow, L. Q., Hwu, W. J., Topalian, S. L., Hwu, P., et al. (2012). Safety and activity of anti-PD-L1 antibody in patients with advanced cancer. New England Journal of Medicine, 366(26), 2455-2465.

52. Gatenby, R. A. (2009). A change of strategy in the war on cancer. Nature, 459(7246), 508-509.

53. Wieder, T., Braumüller, H., Kneilling, M., Pichler, B., \& Röcken, M. (2008). T cell-mediated help against tumors. Cell Cycle, 7(19), 2974-2977.

54. Wieder, T., Braumüller, H., Brenner, E., Zender, L., \& Röcken, M. (2013). Changing T-cell enigma: cancer killing or cancer control? Cell Cycle, 12(19), 3146-3153.

55. Finn, O. J. (2008). Cancer immunology. New England Journal of Medicine, 358(25), 2704-2715.

56. Schreiber, R. D., Old, L. J., \& Smyth, M. J. (2011). Cancer immunoediting: integrating immunity's roles in cancer suppression and promotion. Science, 331(6024), 1565-1570.

57. Bruyere, C., \& Meijer, L. (2013). Targeting cyclin-dependent kinases in anti-neoplastic therapy. Current Opinion in Cell Biology, 25(6), 772-779.

58. Collado, M., Gil, J., Efeyan, A., Guerra, C., Schuhmacher, A. J., Barradas, M., et al. (2005). Tumour biology: senescence in premalignant tumours. Nature, 436(7051), 642.

59. Lasorella, A., Benezra, R., \& Iavarone, A. (2014). The ID proteins: master regulators of cancer stem cells and tumour aggressiveness. Nature Reviews: Cancer, 14(2), 77-91.

60. Folkman, J., \& Ingber, D. (1992). Inhibition of angiogenesis. Seminars in Cancer Biology, 3(2), 89-96.
61. Hanahan, D., \& Weinberg, R. A. (2011). Hallmarks of cancer: the next generation. Cell, 144(5), 646-674.

62. Daniel, P. T., Wieder, T., Sturm, I., \& Schulze-Osthoff, K. (2001). The kiss of death: promises and failures of death receptors and ligands in cancer therapy. Leukemia, 15(7), 1022-1032.

63. Trapani, J. A., \& Smyth, M. J. (2002). Functional significance of the perforin/granzyme cell death pathway. Nature Reviews: Immunology, 2(10), 735-747.

64. Thiery, J., \& Lieberman, J. (2014). Perforin: a key pore-forming protein for immune control of viruses and cancer. Sub-Cellular Biochemistry, 80, 197-220.

65. Gao, J., Shi, L. Z., Zhao, H., Chen, J., Xiong, L., He, Q., et al. (2016). Loss of IFN-gamma pathway genes in tumor cells as a mechanism of resistance to anti-CTLA-4 therapy. Cell, 167(2), 397-404.e399.

66. Dorand, R. D., Nthale, J., Myers, J. T., Barkauskas, D. S., Avril, S., Chirieleison, S. M., et al. (2016). Cdk5 disruption attenuates tumor PD-L1 expression and promotes antitumor immunity. Science, 353(6297), 399-403.

67. Pencik, J., Schlederer, M., Gruber, W., Unger, C., Walker, S. M., Chalaris, A., et al. (2015). STAT3 regulated ARF expression suppresses prostate cancer metastasis. Nature Communications, 6 , 7736.

68. Hortobagyi, G. N., Stemmer, S. M., Burris, H. A., Yap, Y. S., Sonke, G. S., Paluch-Shimon, S., et al. (2016). Ribociclib as firstline therapy for HR-positive, advanced breast cancer. New England Journal of Medicine, 375(18), 1738-1748.

69. Parrinello, S., Coppe, J. P., Krtolica, A., \& Campisi, J. (2005). Stromal-epithelial interactions in aging and cancer: senescent fibroblasts alter epithelial cell differentiation. Journal of Cell Science, 118 (Pt 3), 485-496.

70. Wieder, T., Orfanos, C. E., \& Geilen, C. C. (1998). Induction of ceramide-mediated apoptosis by the anticancer phospholipid ana$\log$, hexadecylphosphocholine. Journal of Biological Chemistry, 273(18), 11025-11031.

71. Gillies, R. J., Verduzco, D., \& Gatenby, R. A. (2012). Evolutionary dynamics of carcinogenesis and why targeted therapy does not work. Nature Reviews: Cancer, 12(7), 487-493.

72. Kayser, S., Bobeta, C., Feucht, J., Witte, K. E., Scheu, A., Bulow, H. J., et al. (2015). Rapid generation of NY-ESO-1-specific CD4 T1 cells for adoptive T-cell therapy. Oncoimmunology, 4(5), e1002723.

73. Prokop, A., Wrasidlo, W., Lode, H., Herold, R., Lang, F., Henze, G., et al. (2003). Induction of apoptosis by enediyne antibiotic calicheamicin thetaII proceeds through a caspase-mediated mitochondrial amplification loop in an entirely Bax-dependent manner. Oncogene, 22(57), 9107-9120.

74. Kaplon, J., Zheng, L., Meissl, K., Chaneton, B., Selivanov, V. A., Mackay, G., et al. (2013). A key role for mitochondrial gatekeeper pyruvate dehydrogenase in oncogene-induced senescence. Nature, 498(7452), 109-112.

75. Blagosklonny, M. V. (2012). Cell cycle arrest is not yet senescence, which is not just cell cycle arrest: terminology for TOR-driven aging. Aging (Albany NY), 4(3), 159-165.

76. Finley, L. W., Carracedo, A., Lee, J., Souza, A., Egia, A., Zhang, J., et al. (2011). SIRT3 opposes reprogramming of cancer cell metabolism through HIF 1alpha destabilization. Cancer Cell, 19(3), 416428.

77. Tannahill, G. M., Curtis, A. M., Adamik, J., Palsson-McDermott, E. M., McGettrick, A. F., Goel, G., et al. (2013). Succinate is an inflammatory signal that induces IL-1beta through HIF-1alpha. Nature, 496(7444), 238-242. 